\title{
Enhanced Thermal Stability in Nanostructured Bainitic Steel
}

\author{
C. N. Hulme-Smith ${ }^{\text {a }}$ I. Lonardelli ${ }^{b}$ M. J. Peet ${ }^{a}$ A. C. Dippel ${ }^{c}$ \\ H. K. D. H. Bhadeshia ${ }^{\text {a }}$ \\ ${ }^{a}$ Materials Science and Metallurgy, University of Cambridge, U.K. \\ ${ }^{\mathrm{b}}$ Materials Engineering and Industrial Technologies, University of Trento, Italy \\ ${ }^{\mathrm{c}}$ Deutsches Electronen-Synchrotron DESY, Hamburg, Germany
}

\begin{abstract}
We report an attempt at increasing the thermal stability of nanocrystalline bainite to tempering heat-treatments, by enhancing the silicon concentration of the alloy. Validation experiments have been conducted using synchrotron X-radiation during tempering heat treatment. It is found that the change in alloying successfully stabilises the austenite at elevated temperatures by retarding cementite formation to temperatures as high as $500^{\circ} \mathrm{C}$. Other changes reflected in the lattice parameters of the major phases have revealed further information about the mechanisms involved.
\end{abstract}

Key words: : nanostructured bainite, thermal stability, synchrotron radiation, silicon, cementite precipitation

Nanostructured carbide-free bainitic steel consists of very thin plates of bainitic ferrite in an interconnected network of retained austenite, with a thickness ranging between 20 and $100 \mathrm{~nm}$. These steels exhibit resistance to tempering as measured by the change in hardness $[1,2]$, since retained austenite decomposes to a dispersion of carbides at the plate boundaries, which act to slow coarsening, even at severely high temperatures [3]. However, austenite is regarded as a desirable phase since retained austenite can enhance the ductility and increases the work hardening rate, retarding plastic instability [4-6]. The likely explanation is that formation of strain-induced martensite causes a redistribution of stresses and changes the composite characteristics [7-9]. Stabilisation of retained austenite would enable surface treatment at elevated temperatures after the nanoscale grain structure is produced. Galvanising treatments or

$\overline{1}$ C. Hulme-Smith gratefully acknowledges funding from EPSRC and Rolls-Royce plc

Preprint submitted to Elsevier Science

19 March 2013 
the application of corrosion-resistant coatings subject steel to temperatures of $400-500^{\circ} \mathrm{C}$ for a short time. Without modification, these temperatures are known to remove all of the retained austenite after 15 minutes, as measured ex-situ using conventional X-ray and transmission electron microscopy $[1,2]$. During tempering (heat treatment below the austenite phase field) the steel approaches the equilibrium mixture of ferrite and cementite, usually by a reconstructive process. The power of in-situ synchrotron X-ray diffraction to shed new light was recently shown in the study of the decomposition of retained austenite in Fe-0.39C-4.09Ni-2Si wt\% bainitic steel when using a combination of microscopy, laboratory X-ray diffraction and in-situ synchrotron X-ray experiments $[10,11]$, it was demonstrated that after tempering at $400^{\circ} \mathrm{C}$, the remaining austenite transforms to martensite upon cooling to room temperature. This is due to the precipitation of carbides that deplete the austenite of carbon reducing its stability. It was also found that the austenite films 20$40 \mathrm{~nm}$ in width were less stable than those with a thickness of 100-200 nm. This is because the thinner films of austenite are more enriched in carbon and so have a greater driving force for cementite precipitation.

The structures resulting from transformation at temperatures circa $200^{\circ} \mathrm{C}$ have been extensively studied in previous work. Initial results [4,12] showed that transformation at these low temperatures resulted in very fine plates of ferrite, and high supersaturation of carbon in the austenite and ferrite, measured by X-ray diffraction. Carbon supersaturation was confirmed by direct measurement using atom probe tomography [13], and indicated that the carbon content in austenite was highly inhomogeneous. In-situ heating using synchrotron X-radiation was used to study the early stages of transformation, and showed that as ferrite formed, it resulted in high levels of carbon supersaturation in the enmeshed austenite films, relative to regions of austenite away from the ferrite.

Recently atom probe tomography was used to study the carbon partitioning at the early stages of the bainitic transformation $[14,15]$. In agreement with previous understanding, the partitioning of carbon into the residual austenite occurs immediately after formation of bainitic ferrite. The bainitic ferrite is also supersaturated in carbon due to the high densities of dislocations in the ferrite, which trap carbon. The recent observations suggest that the ferrite in the vicinity of the austenite grain boundary could trap a significant quantity of carbon, preventing the decarburisation of ferrite. With the same technique, the redistribution of alloying elements was also studied during tempering $[16,17]$. It was observed after tempering at $450^{\circ} \mathrm{C}$ for $30 \mathrm{~min}$, there was no significant redistribution of elements such as silicon and manganese. Moreover, tempering at $400^{\circ} \mathrm{C}$ did not lead to partitioning of carbon from supersaturated ferrite to austenite. The presence of accumulated carbon hetrogeneously dispersed in supersaturated ferrite is consistent with the onset of the carbides observed after tempering at $450^{\circ} \mathrm{C}$ for $30 \mathrm{~min}$. This study describes the effect of tempering at 


\begin{tabular}{lllllllll}
\hline & $\mathrm{C}$ & $\mathrm{Mn}$ & $\mathrm{Mo}$ & $\mathrm{Si}$ & $\mathrm{Co}$ & $\mathrm{Al}$ & $\mathrm{Cr}$ & Others \\
\hline Alloy 1 & 0.84 & 2.26 & 0.25 & 1.78 & 1.55 & 0.044 & 1.47 & $0.11 \mathrm{Cu}, 0.11 \mathrm{~V}, 0.021 \mathrm{Nb}$ \\
Alloy 2 & 1.037 & 1.97 & 0.24 & 3.89 & - & 1.43 & - & - \\
\hline Table 1 & & & & & & & &
\end{tabular}

Table 1

Compositions of the alloys of interest, in weight $\%$

different temperatures for two nanostructured bainitic steels of different silicon content, analysed in-situ using a synchrotron X-ray diffraction technique. Alloy 1 represents development of 'typical' nanostructured bainitic steel, while alloy 2 is an experimental composition designed to achieve transformation to bainite at low-temperature while preventing cementite precipitation to the maximum extent possible, in consideration of thermodynamic criteria [18]. The ultimate goal for this study is to investigate retained austenite decomposition and lattice parameter changes, showing the variation in carbon content in real time as decomposition proceeds. These results add to the understanding of the strategies for enhancement of thermal stability of these steels.

Cylindrical samples of $2 \mathrm{~mm}$ diameter and $10 \mathrm{~mm}$ length were machined from the isothermally transformed material (two bainitic steels, with compositions given in table 1: alloy 1 transformed at $215^{\circ} \mathrm{C}$ and alloy 2 transformed at $250^{\circ} \mathrm{C}$ ) for in-situ continuous heating up to $650^{\circ} \mathrm{C}$ and high temperature isothermal experiments $\left(450^{\circ} \mathrm{C}-550^{\circ} \mathrm{C}\right)$. Alloy 2 was transformed at a higher temperature due to its higher carbon content, which would otherwise retard the bainite transformation.

The experiment was carried out on the synchrotron facility at the P02.1 beamline at DESY, Germany. During heating at $5^{\circ} \mathrm{C} / \mathrm{min}$ from room temperature to $650^{\circ} \mathrm{C}$ using a hot air blower, the samples were exposed to an X-ray beam of monochromatic wavelength $\lambda=0.2069 \AA(60 \mathrm{keV})$ with a beam size of $1.2 \mathrm{~mm} \times 1.0 \mathrm{~mm}$. Transmission diffraction patterns were recorded using a flat 2D solid-state detector, mounted perpendicular to the incident beam behind the sample. The sample to detector distance was $1300 \mathrm{~mm}$. A silicon powder standard was used to calibrate the sample to detector distance and refine instrumental parameters. The image data were processed using MAUD (Materials Analysis Using Diffraction), a Rietveld code written in Java $[19,20]$. Each TIFF image with 32 bit dynamic range was integrated over $360^{\circ}$ and converted to spectral data for the Rietveld refinement.

Transmission electron microscopy (TEM) was used to investigate the microstructure of alloy 2 (the microstructure of alloy 1 is shown elsewhere [6]) in which nano-scale ferrite plates are embedded in a network of retained austenite with a thickness ranging between 20 and $150 \mathrm{~nm}$ (figure 1a). The ex-situ tempering at $450^{\circ} \mathrm{C}, 1 \mathrm{~h}$ and $550^{\circ} \mathrm{C}, 1 \mathrm{~h}$ were performed on alloy 2 and the bright field TEM images are displayed in figures $1 \mathrm{~b}, \mathrm{c}$, d. It is clear that in 
alloy 2 after tempering at $450^{\circ} \mathrm{C}$ for $1 \mathrm{~h}$, there is no carbide formation and the retained austenite content is maintained at ( $46 \pm 1$ vol.\%). The morphology of the film is identical to the untempered material. Figure 1c demonstrates the persistence of coarse retained austenite after tempering at $550^{\circ} \mathrm{C}$ for $1 \mathrm{~h}$ and also documents carbide precipitation, as does figure $1 \mathrm{~d}$. The carbides were identified as cementite and orthorhombic iron-silicon carbide (FeSi)C [21] by means of X-ray diffraction in the synchrotron (supplementary figure 1). Postmortem TEM investigation is not sufficient to have a complete picture of the mechanisms involved during tempering, and cannot explain why alloy 2 is much more thermally stable. The progress of transformation during in-situ tempering can be investigated using high-energy synchrotron X-ray diffraction.

Figure 2 shows the experimental 2D plots describing the evolution of $\{111\}$ and $\{200\}$ austenite peaks and $\{110\}$ ferrite peak for both steels, during insitu heating of the isothermally generated mixture of fine bainite and retained austenite, to $650^{\circ} \mathrm{C}$ from room temperature, with a heating rate of $5{ }^{\circ} \mathrm{C} / \mathrm{min}$. The positions of the $\{111\}$ and $\{200\}$ austenite peaks show a maximum lattice parameter at approximately $400^{\circ} \mathrm{C}$ for alloy 1 and $520^{\circ} \mathrm{C}$ for alloy 2 , with a significant reduction at higher temperatures. During the continuous heating experiment, retained austenite starts to decompose at $400^{\circ} \mathrm{C}$ for alloy 1 and at $580^{\circ} \mathrm{C}$ for alloy 2 (figure $3 \mathrm{a}$ ).

The difference in behaviour between the two alloys is confirmed by looking at the evolution of lattice parameters during isothermal tempering at $520^{\circ} \mathrm{C}$ (figure $4 \mathrm{a}$ and $\mathrm{b}$ ). For alloy 1 the depletion of carbon from retained austenite and bainitic ferrite is simultaneous and may be described by an exponential law. In the case of alloy 2, the retained austenite shows a linear behaviour while the lattice parameter of bainitic ferrite drops down very quickly but starts to increase linearly after 50 minutes. If we assume that changes in lattice parameter are correlated with the fluctuation of carbon content, the bainitic ferrite in alloy 2 becomes enriched with carbon when the decomposition rate of the retained austenite increases (figure $3 \mathrm{~b}$ ).

The supersaturated ferrite lattice starts to deviate from linear thermal expansion at $400-420^{\circ} \mathrm{C}$ for alloy 1 , and at approximately $450^{\circ} \mathrm{C}$ for alloy 2 . For both alloys the loss of carbon in austenite and supersaturated ferrite is clearly evident. After formation of a bulk nanoscale bainitic microstructure, the retained austenite is unable to accommodate all the carbon that is rejected from the ferrite [6]. The carbon enrichment of retained austenite is first controlled by diffusion in ferrite, but is subsequently limited by diffusion in austenite [10]. During continuous heating, austenite was not enriched by carbon from supersaturated ferrite. During isothermal holding at $520^{\circ} \mathrm{C}$ for $2 \mathrm{~h}$, alloy 2 displayed unexpected behaviour whereby the lattice parameter of bainitic ferrite started to increase after tempering for 50 minutes (figure 4a). It is possible that the 
increase is associated with the formation of new ferrite from the decomposition of austenite, with a somewhat different chemical composition due to partitioning of substitutional solutes during carbide precipitation.

Dilatometric study of both alloys at $450^{\circ} \mathrm{C}, 500^{\circ} \mathrm{C}$ and $550^{\circ} \mathrm{C}$ is recorded in figure $3 \mathrm{c}$. The volume contraction during retained austenite decomposition is the result of the loss of carbon from the retained austenite. Both alloys have a significant quantity of retained austenite with very high carbon content. For this reason the retained austenite lattice parameter is expected to be large from calculation [22]. Austenite decomposition leads to cementite formation and removes carbon from solution, which leads to a volume contraction manifested as a macroscopic reduction in sample length. The trend agrees with the expected change in lattice parameters for the calculated composition and phase fraction changes during decomposition.

It has been possible to produce nanostructured bainite with enhanced thermal stability above $500^{\circ} \mathrm{C}$. The implications are significant and these observations could open new possibilities for high temperature applications. Moreover, insitu high energy synchrotron X-ray diffraction experiments revealed an interesting and unexpected insight into the dynamics of the phase transformations during tempering in terms of quantitative phase analysis and changes in carbon content of retained austenite and bainitic ferrite.

It should be noted that there are difficulties in using silicon-rich steels which have to be surface treated (e. g. galvanising) [23]. In such circumstances it would be appropriate to reduce the silicon concentration and enrich that of aluminium which serves the same purpose.

\section{References}

[1] C. Garcia-Mateo, M. Peet, F. G. Caballero, H. K. D. H. Bhadeshia: Mat. Sci. Techn. 20 (2004) 814.

[2] M. J. Peet: Transformation and tempering of low-temperature bainite: Ph.D. thesis: Univ. of Cambridge (2010).

[3] H. S. Hasan, M. J. Peet, H. K. D. H. Bhadeshia: Int. J. Mat. Res. 103 (2012) 1319.

[4] F. G. Caballero, H. K. D. H. Bhadeshia, K. J. A. Mawella, D. G. Jones, P. Brown: Mat. Sci. Techn. 18 (2002) 279.

[5] F. G. Caballero, H. K. D. H. Bhadeshia: Curr. Opin. Sol. St. Mat. Sci. 8 (2004) 251.

[6] H. K. D. H. Bhadeshia: Proc. Roy. Soc. A 466 (2010) 3. 
[7] M. Sherif, C. Garcia-Mateo, T. Sourmail, H. K. D. H. Bhadeshia: Mat. Sci. Techn. 20 (2004) 319.

[8] Y. Tomota, K. Kuroki, T. Mori, I. Tamura: Mat. Sci. Engng. 24 (1976) 85.

[9] H. K. D. H. Bhadeshia, D. V. Edmonds: Met. Sci. 14 (1980) 41.

[10] A. S. Podder, I. Lonardelli, A. Molinari, H. K. D. H. Bhadeshia: Proc. Roy. Soc. A 467 (2011) 3141.

[11] A. Saha Podder, H. K. D. H. Bhadeshia: Mat. Sci. Engng. A 527 (2010) 21218.

[12] C. Garcia-Mateo, F. G. Caballero, H. K. D. H. Bhadeshia: ISIJ Int. 43 (2003) 1821.

[13] M. Peet, S. S. Babu, M. K. Miller, H. K. D. H. Bhadeshia: Scripta Mat. 50 (2004) 1277.

[14] F. G. Caballero, M. Miller, C. Garcia-Mateo: Acta Mat. 59 (2010) 2338.

[15] F. G. Caballero, M. K. Miller, S. S. Babu, C. Garcia-Mateo: Acta Mat. 55 (2007) 381.

[16] F. G.Caballero, M. K.Miller, A. J.Clarke, C. Garcia-Mateo: Acta Mat. 63 (2010) 442

[17] F. G. Caballero, M. Miller, C. Garcia-Mateo, C. Capdevila, S. Babu: Acta Mat. 56 (2008) 188.

[18] M. J. Peet, H.K.D.H. Bhadeshia: Unpublished work: University of Cambridge, U.K. (2010).

[19] L. Lutterotti, S. Matthies, H. R. Wenk, A. S. Shultz, J. W. Richardson: J. App. Phys. 81 (1997) 594.

[20] H. M. Rietveld: J. App. Cryst. 2 (1969) 65.

[21] J. M. Schissler, J. Arnould, G. Metauer: Mem. Sci. Rev. Metallurg. 72 (1975) 779 .

[22] H. K. D. H. Bhadeshia, S. A. David, J. M. Vitek, R. W. Reed: Mat. Sci. and Techn. 7 (1991) 686.

[23] B. C. De Cooman, Curr. Opin. Solid. St. M. 8 (2004) 285 


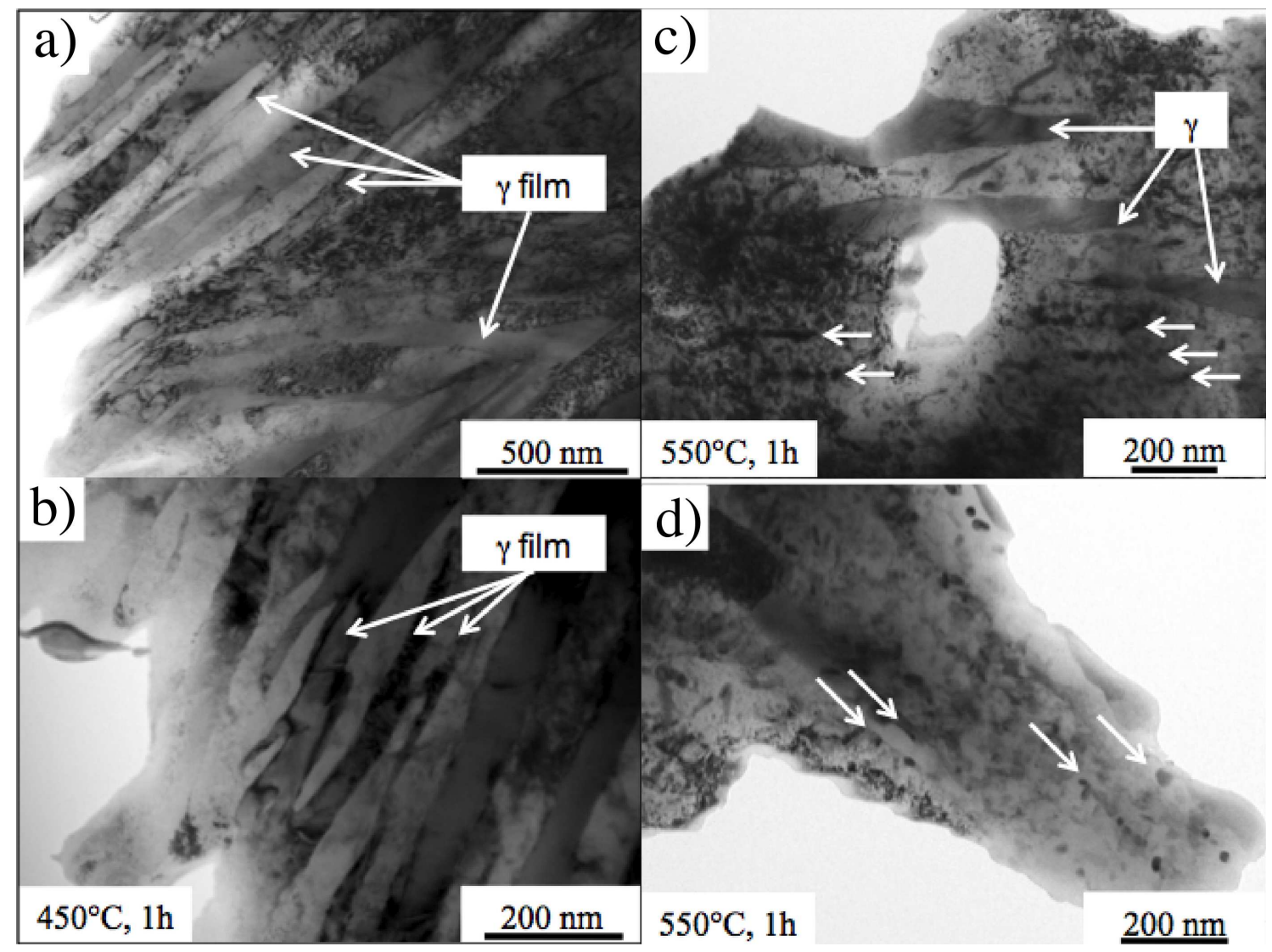

Fig. 1. Bright field TEM images of Alloy 2 after (a) austempering at $250^{\circ} \mathrm{C}$, (b) tempering at $450^{\circ} \mathrm{C}, 1 \mathrm{~h}$. (c), (d) tempering at $550^{\circ} \mathrm{C}, 1 \mathrm{~h}$. Unless otherwise labelled, arrows denote carbides.

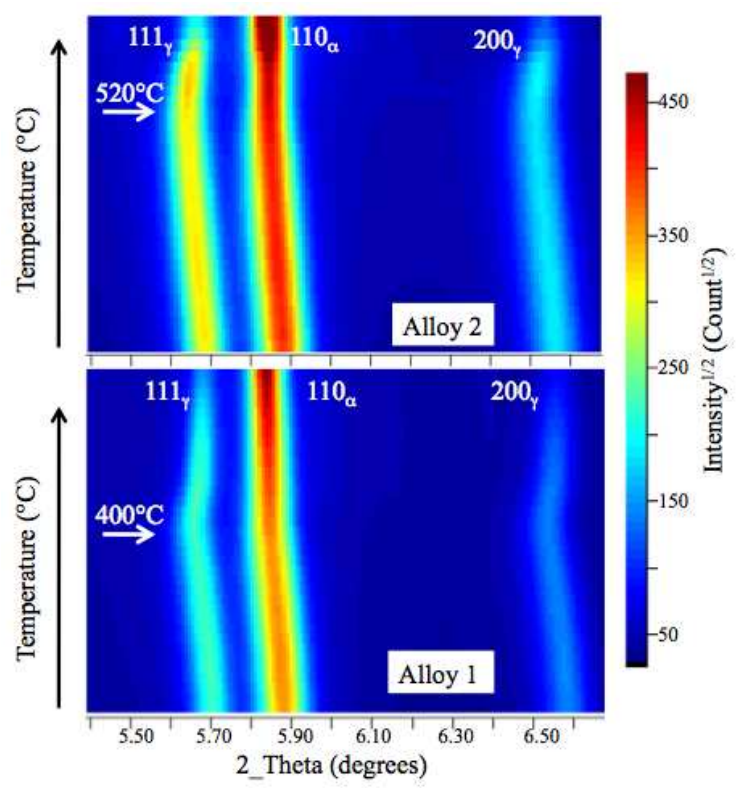

Fig. 2. Experimental 2D plots of the evolution of retained austenite and bainitic ferrite during continuous heating. 


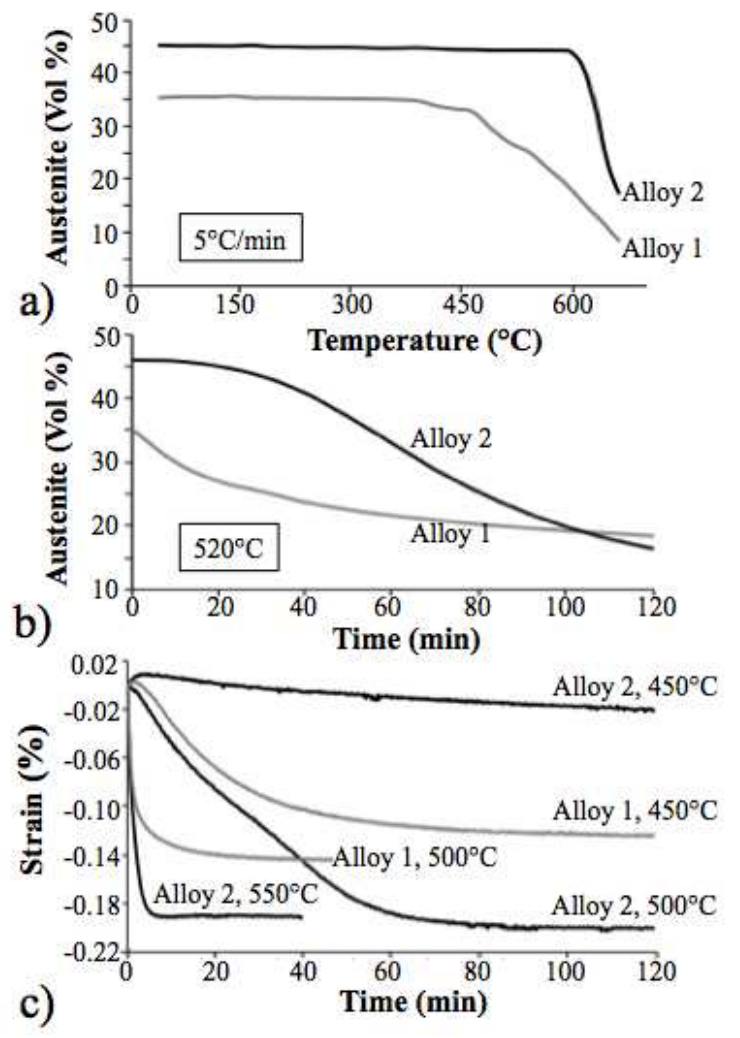

Fig. 3. Evolution of retained austenite during (a) continuous heating and (b) isothermal heating at $520^{\circ} \mathrm{C}$, (c) dilatometric measurements of strain (\%) during isothermal tempering. 


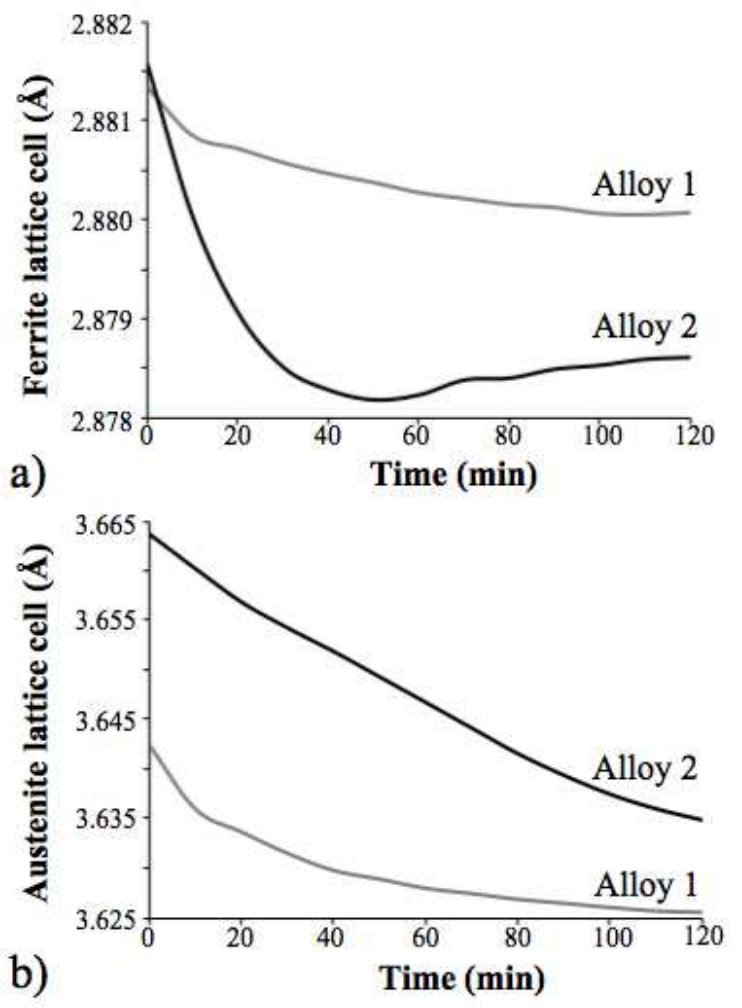

Fig. 4. Lattice parameter changes of bainitic ferrite (a) and retained austenite (b) during isothermal tempering at $520^{\circ} \mathrm{C}$. 